\title{
Особенности формирования фазового и элементного состава при электроискровом легировании ручным вибратором повышенной частоты
}

\author{
А. В. Коваль \\ Институт прикладной физики, \\ 2. Кишинев, МD-2028, Молдова, е-таil: sasha.covali@mail.ru \\ Поступила в редакцию 14.04.2021 \\ После доработки 02.06.2021 \\ Принята к публикации 04.06.2021
}

\begin{abstract}
Исследован фазовый и элементный состав электроискровых покрытий из никеля и титана, полученных на стали, никеле и титане, покрытий из ТНМ-20 и ВК8 на стали при высокочастотном электроискровом легировании. Установлено, что материал электрода, подложки и режимы нанесения оказывают основное влияние на физико-химические свойства покрытий. Показано положительное влияние высокочастотного легирования на качественные показатели обработанных поверхностей. Фазовый и химические анализы свидетельствуют о наличии соединений, улучшающих коррозионную стойкость обрабатываемых поверхностей. Легирование электродами ВК8 на высокой частоте обеспечивает повышенное содержание карбида вольфрама в нанесенном слое.
\end{abstract}

Ключевые слова: электроискровое легирование, высокочастотное легирование, фазовый состав, химический состав, сталь, титан, никель, ТНМ-20, ВК8

\section{УдК 621.755 \\ https://doi.org/10.52577/eom.2021.57.6.14 ВВЕДЕНИЕ}

В машиностроении используется широкий ассортимент сталей, которые применяют не только при изготовлении инструментов (режущих, измельчающих и др.), но и деталей машин, станков и различного оборудования. При этом, обладая высокой твердостью, они часто имеют низкую коррозионную стойкость. Для ее повышения, а также износостойкости используются различные физико-химические методы (вакуумное напыление, лазерная наплавка, осаждение и др.) [1-4]. Но данные методы сложны и энергозатратны.

На протяжении многих лет метод электроискрового легирования (ЭИЛ) используется для изменения физико-химических свойств обрабатываемых поверхностей. При ЭИЛ происходит не только нанесение материала электрода (анода) на обрабатываемую поверхность (катод), но и ее модификация в результате многократного воздействия концентрированных импульсных разрядов. Свойства полученного электроискрового покрытия (ЭИП) зависят от фазового состава электродов и окружающей среды, технологических и энергетических параметров процесса ЭИЛ.

В силу происходящих скоростных микрометаллургических процессов (нагрев и испарение из-за высокой температуры в канале разряда (5000-25000 $\left.{ }^{\circ} \mathrm{K}\right)$, затвердевание со скоростями до $10^{5}-10^{6}$ К К) и разных коэффициентов термического расширения на наносимых покрытиях появляются микротрещины. В сильно агрессивных средах это приводит к протравливанию основного металла и осыпанию покрытия [5]. Так, в работе [6] при исследованиях покрытий WC-Co на инструментальной стали H13 было показано, что для получения качественных покрытий необходимо соблюдать определенный баланс энергии и частоты импульсов. При высоких энергиях увеличивается твердость и толщина покрытий, но резко возникают риски получения трещин в покрытиях как продольных, так и поперечных. При снижении энергии получают менее толстое покрытие, но зато более плотное и однородное. Трещины могут присутствовать, но они в основном продольные.

Другой путь повышения качественных характеристик покрытий - комбинация разных материалов для получения сложных соединений или нанесение многослойных покрытий. Так, для улучшения пластичности используют никель, кобальт или медь.

Исследования показали [7], что покрытия из карбидов и нитридов титана, карбида хрома, карбида вольфрама (с кобальтовой связкой) повышают не только износостойкость, но и коррозионную стойкость основы. Было установлено, что применение никелевых сплавов (с хромом или медью) для ЭИЛ стальных 
деталей значительно повышает коррозионную стойкость в морской [8] и соленой воде, насыщенной хлор-ионами [9], что позволяет заменять хромовые покрытия, например, в кораблестроении [8]. Хотя никель чувствителен к агрессивным воздействиям, его положительное влияние на уменьшение скорости коррозии, возможно, объясняется образованием различных стойких соединений, в том числе никелидов, интерметаллидов. При попеременном легировании стали титаном-никелем или никелем-титаном ставится задача обеспечения таких условий процесса, при которых возможно образование соединений TiNi (например, TiNi, $\mathrm{Ti}_{2} \mathrm{Ni}$ и $\mathrm{TiNi}_{3}$ ), которые улучшают коррозионную стойкость покрытий.

Результаты исследований ЭИП из ТiC, WC, Мо на нержавеющей стали [10] показали, что в соленой среде $(5 \% \mathrm{NaCl})$ значительно снижает токи коррозии молибден ( в 350 раз), а также карбид титана ( в 30 раз). Снижение коррозии молибденом исследователи объясняют большей равномерностью нанесенного слоя по сравнению с карбидом вольфрама или титана. В то же время молибденовое покрытие наименее износостойкое.

Другие исследователи проводили ЭИЛ стали Ст45 электродами Ti, Mo и Сu [11]. Причем медь использовалась с двойной целью: создание антифрикционного покрытия, а также снижение остаточных напряжений. После легирования проводили лазерную обработку. Замечено, что двойные покрытия наиболее перспективны: они обеспечивают не только высокую износостойкость, но и высокую коррозионную стойкость. При этом покрытие с молибденом (Cu-Mo, Cu-Mo+laser) оказалось более коррозионностойким, чем с титаном. Однако при легировании спеченными сплавами с ТіС лучше использовать никель, поскольку медь обладает плохой смачиваемостью с частицами ТіС [12].

Кроме титановых соединений для ЭИЛ широко применяются и вольфрамовые. Образующиеся в результате обработки соединения (WC, $\mathrm{W}_{2} \mathrm{C}$, их $\alpha$ и $\beta$ фазы) [13] значительно улучшают физико-химические характеристики обработанных поверхностей [6, 14-18]. В качестве электродов использовались как классические с кобальтом (BK8 или WC92-Co8), так и WC-Cu c различными соотношениями меди, в результате чего удалось значительно улучшить коррозионную стойкость сталей (С45 и С52). Но в силу большой разницы в физических характеристиках материалов (температура плавления, теплопроводность) покрытия с медью (как и в случае с титаном) получаются неоднородными, с включениями твердых частиц вольфрама. Для придания им однородности используют лазер, что на практике бывает затруднительно или невозможно из-за сложности обрабатываемых деталей или мест обработки. Исходя из вышесказанного, наиболее перспективными и универсальными добавками являются никель и кобальт.

Повышение частоты легирования не только за счет искровых импульсов, но за счет использования нового высокочастотного вибратора позволяет по-новому подойти к процессу модификации поверхности [19]. Достигаемый при высоких частотах (до 2000 Гц) интегральный эффект накопления энергии позволяет уменьшить шероховатость и повысить однородность получаемых покрытий. В работе [20] приведены результаты исследований сравнительной коррозионной стойкости в кислых, щелочных и нейтральных средах как чистых металлов (сталь, никель, титан), так и электроискровых покрытий из никеля и титана, полученных на стали при высокочастотном электроискровом легировании. Однако ограниченный объем статьи не позволил уделить внимание особенностям формирования фазового и элементного состава ЭИП при высокочастотном легировании. А это достойно внимания для сравнения, поскольку значительное количество исследований фазового состава проводится для покрытий, полученных при использовании вращающихся электродов.

В данной работе приведены результаты исследования фазового и элементного состава покрытий, полученных при легировании титаном никеля и титана, никеля - титаном, стали - сплавами ТНМ-20 и ВК8. Дополнительно проведено исследование коррозионного поведения покрытий ВК8, ТНМ-20 и Ti-Ni на стали при ЭИЛ ручным вибратором, работающим на повышенной частоте (1000 Гц).

\section{МЕТОДИКА ЭКСПЕРИМЕНТА}

В качестве подложки были использованы образцы из стали Ст.3 с рабочей поверхностью около $1 \mathrm{~cm}^{2}$. Использовались металлы: йодидный титан чистотой $99,95 \%$; электролитический никель (НЭ) чистотой 99,9\%, переплавленный в электронно-лучевой печи в атмосфере очищенного гелия, а затем прокатанный до толщины 10 мм, безвольфрамовый твердый сплав ТНМ-20, содержащий вес. \%: ТiC - 80, $\mathrm{Ni}-15$, Mo -5 .

На подложку из стали Ст.3 наносили различные покрытия: титан, никель, титанникель, никель-титан. Обработку проводили на установке для высокочастотного электроискрового легирования ПЭЛ-2000 с высокочастотным вибратором. Покрытия наносили в 
Таблица 1. Значения толщины металла, участвующего в образовании дифракционного отражения

\begin{tabular}{|c|c|c|}
\hline Металл & $\mu, \mathrm{cm}^{-1}$ & Z, мкм \\
\hline $\mathrm{Fe}$ & 542,9 & $4,5-23,9$ \\
\hline $\mathrm{Ni}$ & 828,59 & $3,1-16,5$ \\
\hline $\mathrm{Ti}$ & 1711,6 & $1,5-8,0$ \\
\hline
\end{tabular}

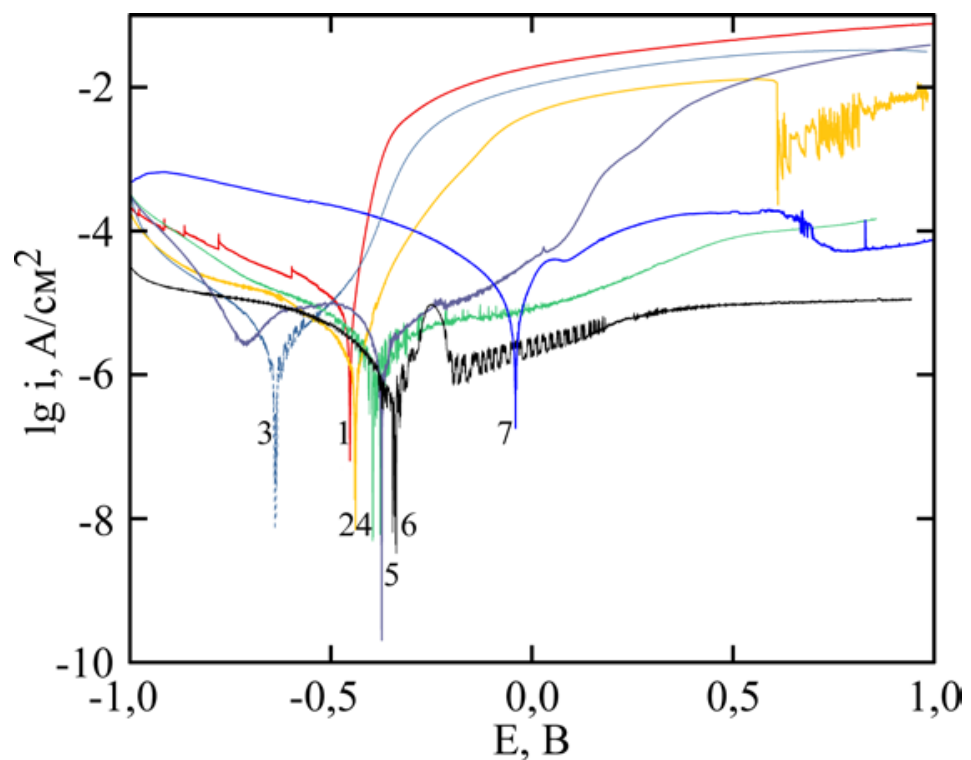

Рис. 1. Поляризационные кривые металлов и покрытий: 1 - Ст.3; 2 - ВК8; 3 - Ст.3-ВК8; 4 - Ст.3-ТНМ-20; 5 - Ni; 6 - Ті; 7 - Ст.3-Ti-Ni.

один слой толщиной до 40-100 мкм (на стали до 80-100 мкм, на никеле или титане 40-60 мкм) на двух режимах: низкочастотный (НЧ) - энергия в импульсе 0,3 Дж при частоте 100 Гц; высокочастотный (ВЧ) - энергия в импульсе 0,08 Дж при частоте 1000 Гц. Удельное время легирования составляло для НЧ режима

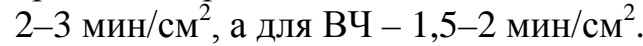

Элементный состав изучали с использованием локального рентгеновского EDX-анализа (INCA Energy EDX). Рентгенофазовый анализ проводили на универсальном дифрактометре ДРОН-3М с использованием обычной рентгеновской дифракции $\left(\mathrm{CoK}_{\alpha}-\right.$ излучение, Fe-фильтр, $\theta / 2 \theta$ метод). Толщина металла $Z$, участвующего в образовании дифракционного отражения, рассчитывалась по формуле из [21] (табл. 1):

$$
Z=\frac{3}{\mu} \times \frac{\sin \alpha \times \sin (2 \theta-\alpha)}{\sin \alpha+\sin (2 \theta-\alpha)}
$$

где $\mu$ - линейный коэффициент поглощения, $\mathrm{cm}^{-1} ; \alpha-$ угол падения пучка.

При обычной съемке методом БреггаБрентано $\alpha=\theta$, тогда $Z=\frac{3 \sin \theta}{2 \mu}$. Угол $\theta$ изменяется в пределах $10-66^{0}$.

Однако величину $Z$ можно вычислить только для чистых металлов, поскольку для покрытий неизвестно значение $\mu$.

Электрохимические исследования покрытий проводили в трехэлектродной электро- химической ячейке. Заданный режим поддерживали с помощью потенциостата ПИ-50-1.1. Потенциалы замеряли относительно хлоридсеребряного электрода, который используют благодаря его стабильности и четкости определения электрохимического потенциала [10]. Коррозионные исследования проводили в нейтральном $(\mathrm{pH}=6,0 \pm 0,1)$ модельном растворе, г/л: $7 \mathrm{NaCl}$ и $7 \mathrm{Na}_{2} \mathrm{SO}_{4}$ методами снятия вольтамперных характеристик. Вольтамперометрические измерения состояли в получении поляризационных кривых в диапазоне от -1 до $+1 \mathrm{~B}$. Скорость задачи потенциала $-1 \mathrm{mB} \cdot \mathrm{c}^{-1}$. Полученные кривые корректировались на величину омического падения напряжения (IR). Экстраполяцией на значение коррозионного потенциала определяли плотность тока коррозии.

\section{РЕЗУЛЬТАТЫ ЭКСПЕРИМЕНТОВ И ИХ ОБСУЖДЕНИЕ. КОРРОЗИОННЫЕ ИСПЫТАНИЯ ПОКРЫТИЙ НА СТАЛИ}

Для коррозионных испытаний покрытия на Ст.3 наносились только на ВЧ режиме, поскольку на нем обеспечивается более высокое качество покрытий. Из чистых металлов сталь Ст.3 обладает наименьшей коррозионной стойкостью и имеет наиболее отрицательное значение потенциала коррозии $(-0,453$ В) среди металлов, не подвергнутых ЭИЛ (рис. 1). Обработка стальной поверхности сплавом ВК8 значительно сдвигает потенциал коррозии в 
Таблица 2. Параметры коррозионного процесса электроискровых покрытий и металлов в нейтральной среде (7 г/л $\mathrm{Na}_{2} \mathrm{SO}_{4}$ и 7 г/л $\mathrm{NaCl}$ )

\begin{tabular}{|c|c|c|c|c|c|c|}
\hline & & & & \multicolumn{3}{|c|}{ Вольт-амперные измерения } \\
\cline { 5 - 7 } $\begin{array}{c}\text { Металл, } \\
\text { покрытие }\end{array}$ & $t,{ }^{\circ} \mathrm{C}$ & $\mathrm{pH}$ & $\rho, \Gamma / \mathrm{cm}^{3}$ & $i_{\text {соrr } \times 10^{-6},}$ & $E_{\text {соrr }}$, В & $\begin{array}{c}\text { Средний } \\
\text { глубинный } \\
\text { показатель, } \\
K_{n}, \text { мм/год }\end{array}$ \\
\hline Ст.3 & 25 & 6 & 7,85 & 4,95 & $-0,453$ & 0,058 \\
\hline Ст.3-ВК8 & 25 & 6 & 7,85 & 1,064 & $-0,635$ & 0,012 \\
\hline Ст.3-ТНМ-20 & 25 & 6 & 7,85 & 1,241 & $-0,390$ & 0,014 \\
\hline Ст.3-Ti-Ni & 25 & 6 & 7,85 & 2,483 & $-0,043$ & 0,029 \\
\hline $\mathrm{Ni}$ & 25 & 6 & 8,9 & 2,805 & $-0,370$ & 0,030 \\
\hline Ti & 25 & 6 & 4,4 & 0,637 & $-0,326$ & 0,008 \\
\hline
\end{tabular}

отрицательную сторону по сравнению с чистой сталью (-0,635 против -0,453В). При этом достигается самое значительное снижение тока коррозии (почти в 5 раз) среди нанесенных покрытий. ЭИЛ сплавом ТНМ-20, наоборот, облагораживает потенциал $(-0,390$ В). Хочется отметить, что такая же тенденция наблюдалась и в работе [10], когда проводили ЭИЛ вращающимся электродом нержавеющей стали 304 электродами WC95-Co5 и TiC95-Ni5. Потенциал коррозии разблагораживался с -163 мВ для нержавеющей стали до -309 мВ WC95-Co5 и -272 мB TiC95-Ni5. При этом для WC95-Co5 наблюдалось снижение на порядок тока коррозии относительно базового металла, в то время как для TiC95-Ni5 он превышал значения для базового металла. Скорее всего, это связано с физическими свойствами (температура плавления) карбидов титана и вольфрама. Увеличение температуры плавления приводит к уменьшению времени нахождения в жидкой фазе. Поскольку карбид титана более тугоплавкий, то полученное покрытие более неоднородно и трещиновато, что ведет к снижению коррозионной стойкости. Кроме того, наиболее сильное влияние на потенциал коррозии оказывает легирование титаном, а потом никелем - потенциал облагораживается до значения $-0,043 \mathrm{~B}$.

По результатам поляризационных измерений определяли скорость коррозии, используя метод экстраполяции. Для большей наглядности был рассчитан глубинный показатель коррозии (или проницаемость) $[18,22]$ :

$$
K_{n}=\frac{3,268 \times i_{\text {corr }} \times M}{n \times \rho},
$$

где $K_{n}$ - глубинный показатель коррозии, мм/год; $i_{\text {corr }}$ - плотность тока коррозии, $\mathrm{MA} / \mathrm{cm}^{2}$; $M$ - атомная масса металла; $n$ - число электронов, принимающих участие в элементарном акте электродной реакции; $\rho-$ плотность

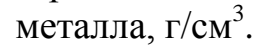

В табл. 2 приведены рассчитанные на основе данных вольт-амперных измерений коррозионные характеристики исследуемых покрытий и необработанных металлов.

Из табл. 2 видно, что самым стойким является чистый титан с минимальным током коррозии (0,637 мкА). По коррозионной активности чистый никель менее коррозионностойкий, чем чистый титан. При этом нанесение на стальную поверхность покрытия $\mathrm{Ti}-\mathrm{Ni}$ уменьшает ток коррозии в 2 раза за счет формирования соединений, уменьшающих коррозионную активность железа в модельной среде. Почти одинаковые величины токов коррозии для $\mathrm{Ni}$ и Ст.3-Ti-Ni, скорее всего, указывают на более активное участие в коррозионном процессе никеля, чем железа [20]. В то же время ток коррозии для данного покрытия в 2 раза больше, чем для покрытий ВК8 и ТНМ-20. Нанесение на сталь ЭИП из безвольфрамового твердого сплава THМ-20, как и ВК8, уменьшает ток коррозии в 4 раза. И это притом (как будет показано далее) что в некоторых случаях в покрытии может содержаться до 70-80\% железа. Снижение величины тока коррозии, вероятно, обусловлено образованными соединениями (аморфными и др.) в нанесенном слое, которые тормозят химическую активность железа.

\section{ФАЗОВЫЙ И ЭЛЕМЕНТНЫЙ АНАЛИЗ ПОКРЫТИЙ}

Результаты легирования стального образца сплавом ВК8 на ВЧ режиме представлены на рис. 2. Фазовый анализ показал, что нанесенный слой на 80\% состоит из железа. Он представлен в виде интенсивных пиков $\gamma$-Fe, а также слабых пиков металла подложки $\alpha$-Fе. Слабое представление последних, возможно, и объясняет хорошую коррозионную стойкость нанесенного слоя. Установлено, что карбид вольфрама, из которого в основном состоит электрод, в процессе легирования переходит в чистый вольфрам и карбид дивольфрама $\mathrm{W}_{2} \mathrm{C}[14,23]$. 


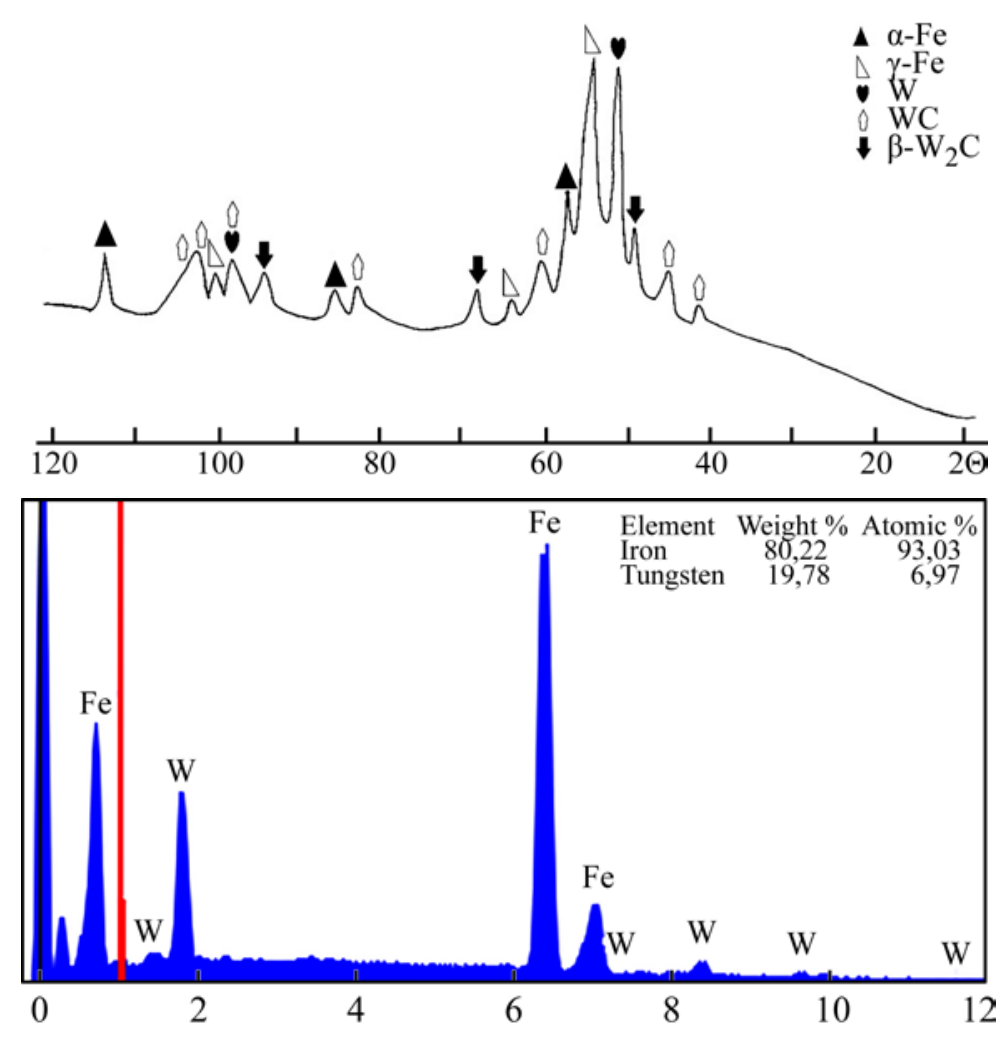

Рис. 2. Дифрактограмма покрытия Ст.3-ВК8: режим ВЧ, EDX-спектр и химический состав поверхности.

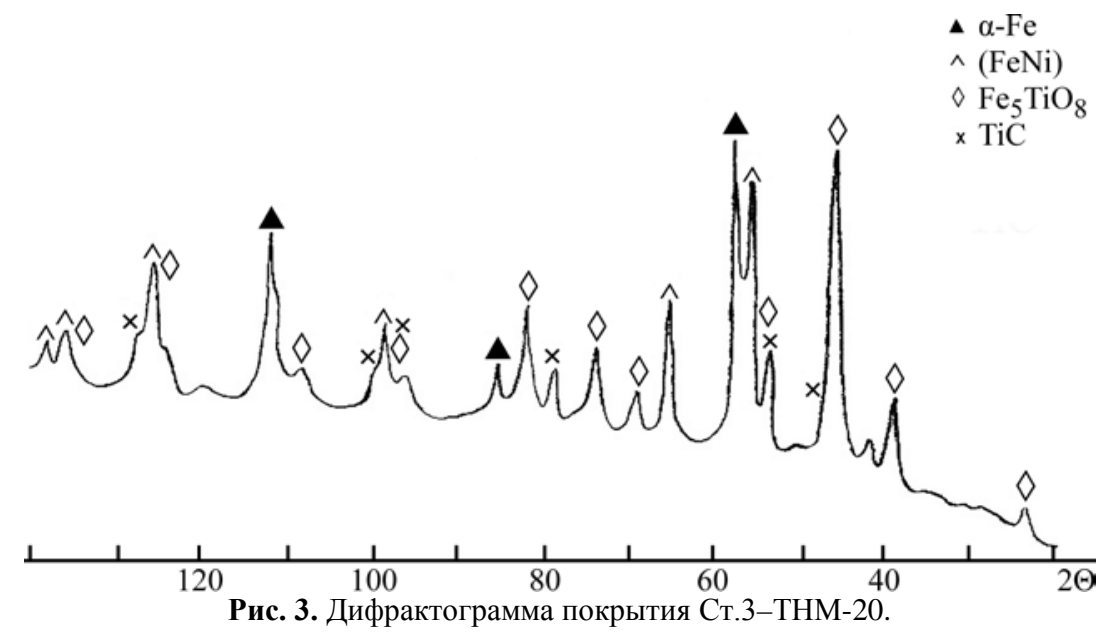

В результате износостойкость покрытия снижается, и чтобы этого избежать, изготавливают электроды с повышенным содержанием углерода. В нашем случае вольфрам в покрытии составляет только около $20 \%$ и представлен как в чистом виде, так и в виде карбида вольфрама, карбида дивольфрама $\beta-\mathrm{W}_{2} \mathrm{C}, \quad$ который существует только при высоких температурах и способствует повышению коррозионной стойкости покрытия [15]. При этом карбид вольфрама присутствует в покрытии довольно равномерно.

Анализ покрытия, полученного на Ст.3 при легировании твердым сплавом ТНМ-20 (состоящим на $80 \%$ из карбида титана) на режиме ВЧ, показал, что молибден в покрытии не фиксируется (рис. 3). На дифрактограмме видны довольно интенсивные, но малочисленные пики материала подложки $\alpha$-Fе и сформированного в процессе легирования твердого раствора $(\mathrm{FeNi})$, хотя в составе твердого сплава никеля всего 15 вес.\%. Титан в покрытии в этом случае присутствует в виде карбида титана ТiC и двойного оксида $\mathrm{Fe}_{5} \mathrm{TiO}_{8}$, причем пики двойного оксида значительно интенсивнее, чем при последовательном легировании стали титаном и никелем или никелем и титаном. Отсутствие молибдена на поверхности покрытия, скорее всего, объясняется либо его участием в составе аморфных соединений, либо его нахождением в глубине покрытия. Хотя он мог просто не обнаружиться в данной точке поверхности все-таки в электроде его только 5\%.

Легирование стали титаном было решено провести сравнительным: только режим НЧ и потом режим ВЧ. Последнее было сделано с 


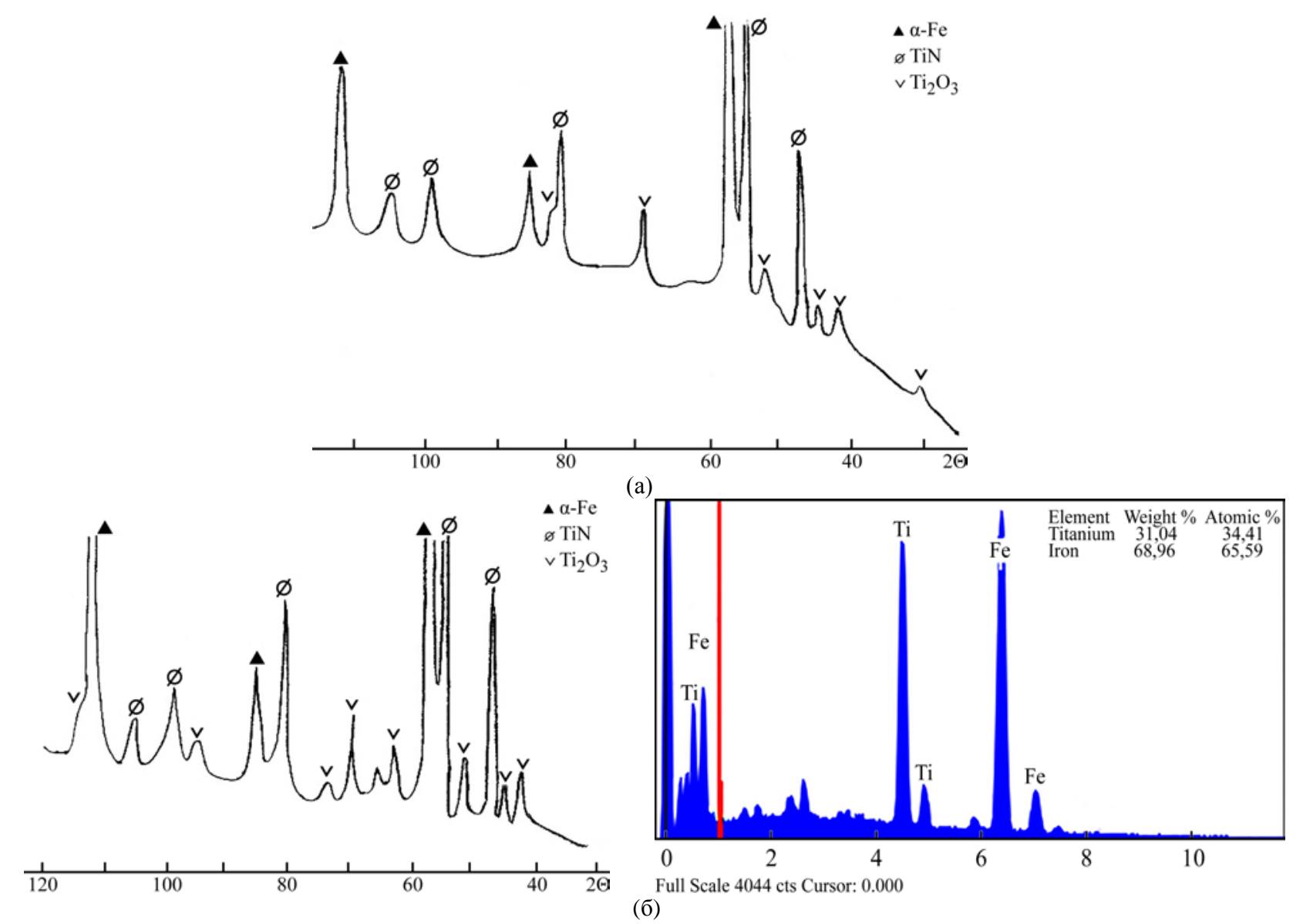

Pис. 4. Дифрактограммы покрытия Ст.3-Ті: режим НЧ (a), режим НЧ+BЧ, его EDX-спектр и химический состав (б).

целью получения максимально сплошного и однородного покрытия. В результате при легировании стали Ст.3 титаном на НЧ режиме (рис. 4а) на дифрактограммах видны сильные пики примерно одной и той же интенсивности $\alpha-\mathrm{Fe}$ подложки и сформированного в процессе легирования нитрида титана TiN. При этом в покрытии видны многочисленные пики средней интенсивности, относящиеся к оксиду титана $\mathrm{Ti}_{2} \mathrm{O}_{3}$.

Если же теперь дополнительно легировать полученное покрытие на ВЧ режиме, то наблюдается близкая к описанному выше картина (рис. 4а,б). Но при этом пики оксида $\mathrm{Ti}_{2} \mathrm{O}_{3}$ проявляются в существенно большей степени. Исследования элементного состава (рис. 4б) свидетельствуют о том, что в покрытии превалирует материал подложки (почти 70\%). Наблюдаемый горб (особенно при НЧ режиме) указывает на то, что в покрытии формируются аморфные соединения, которые, видимо, превалируют при обработке в НЧ режиме.

Необходимо отметить один факт. При легировании Ст.3 ВК8, ТНМ-20, титаном (на НЧ, НЧ+ВЧ режимах) в легированном слое наблюдается значительное количество железа (до 80\%). Такая же тенденция наблюдалась и в работе [10], когда при легировании нержавеющей стали 304 использовались электроды WC95-Co5 и
TiC95-Ni5 и вибратор с вращающимся электродом. При этом емкости конденсаторов составляли 100-150 мкФ, а в нашем случае 50 мкФ (НЧ режим) и 16 мкФ (ВЧ режим). Можно полагать, что, несмотря на значительную разницу в энергии импульсов, основное влияние на состав легированного слоя оказывают физикохимические свойства контактирующих материалов: плотность, температура плавления, теплопроводность и др. Это подтверждается и тем, что в нанесенном слое встречаются целые частицы WC [10]. В нашем случае железо присутствует в основном в виде $\alpha$-Fe. Поскольку ЭИП в ходе затвердевания в большинстве имеют трещины (продольные или поперечные - в зависимости от материалов и энергетических параметров процесса), то наличие $\alpha$-Fe дополнительно оказывает негативное влияние на коррозионную стойкость покрытий. Как вариант, при легировании Ст.3 для уменьшения присутствия материала подложки необходимо увеличить время легирования, энергию импульсов и чередовать слои (ВЧ, НЧ, ВЧ, НЧ). Нахождение оптимальных параметров импульсов требует дополнительных исследований, поскольку, как было сказано вначале в [6], увеличение энергии и толщины покрытий повышает риски поперечных трещин, вплоть до основного материала. И это снова возвращает нас к свойствам контакти- 


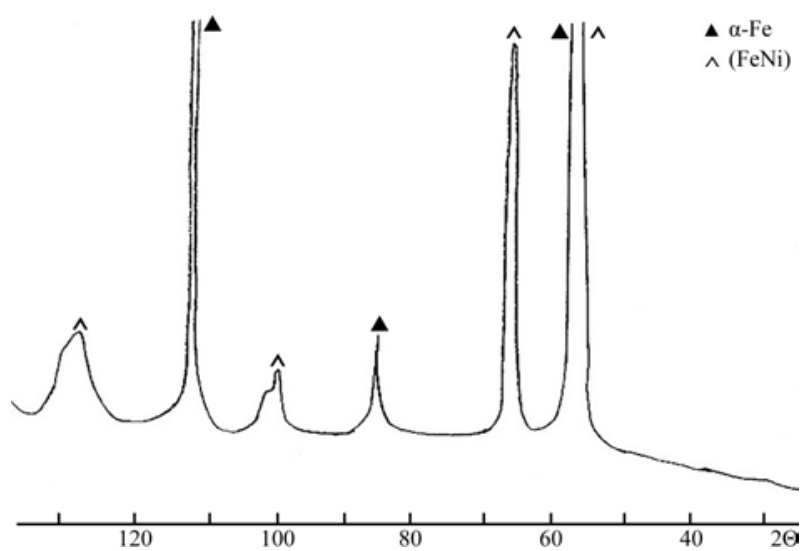

(a)

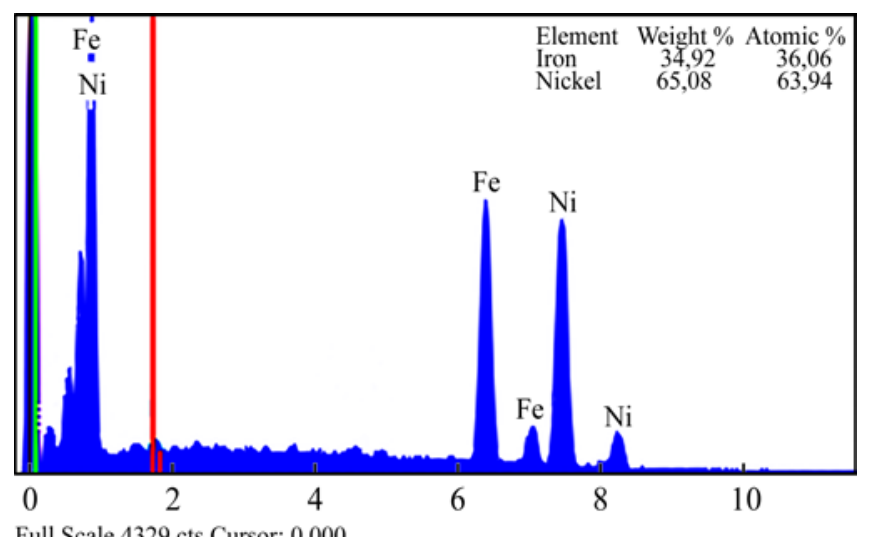

(б)

Рис. 5. Дифрактограммы покрытия Ст.3-Ni (режим BЧ), его EDX-спектр и химический состав.

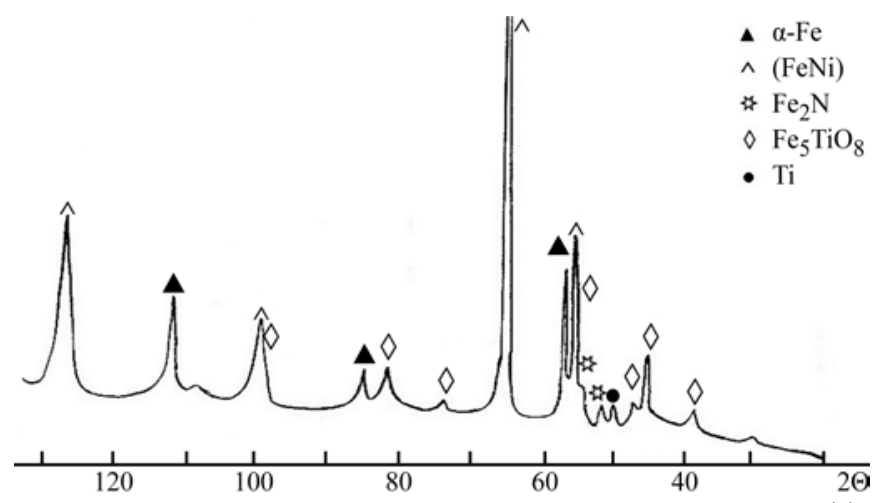

(a)

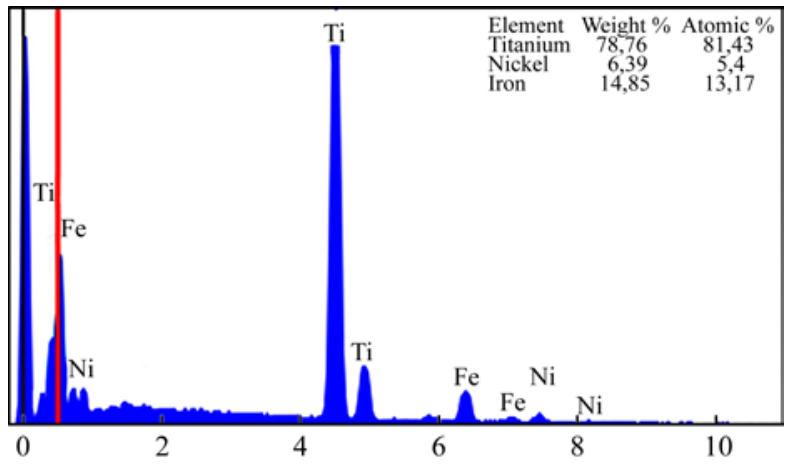

Full Scale 8620 cts Cursor: 0.000
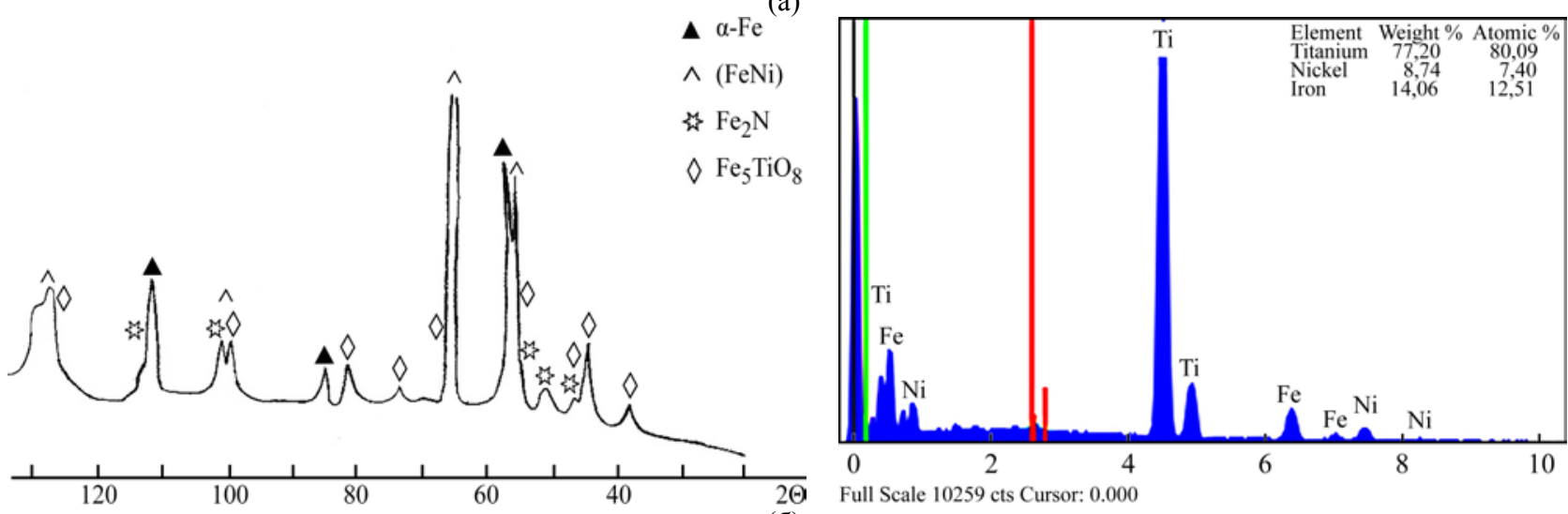

(б)

Рис. 6. Дифрактограммы покрытия: Ст.3-Ni-Ti режим BЧ, EDX-спектр и химический состав (a); Ст.3-Ti-Ni, режим BЧ, EDX-спектр и химический состав (б).

рующих материалов. Исследования показали, что склонность к трещинообразованию у ТіС значительно меньше, чем у WC.

При легировании стали Ст.3 никелем на ВЧ режиме (рис. 5a) на дифрактограммах в покрытии фиксируются сильные пики металла подложки в виде $\alpha$-Fe. Одновременно в покрытии видны не менее интенсивные пики, относящиеся к образованному в процессе легирования твердому раствору (FeNi). Исследования элементного состава покрытия в этом случае свидетельствуют, что содержание в нем никеля почти в два раза превышает содержание материала подложки (рис. 5б).

Интересные результаты были получены при чередовании $\mathrm{Ni}-\mathrm{Ti}$ и Ti-Ni на стали.
При последовательном легировании на ВЧ режиме стали Ст.3 сначала никелем, а потом титаном на дифрактограмме (рис. 6а) на поверхности нанесенного слоя фиксируются интенсивные пики образованного в процессе легирования твердого раствора (FeNi), менее интенсивные пики металла подложки $\alpha$-Fe и сформированного при легировании нитрида железа $\mathrm{Fe}_{2} \mathrm{~N}$. Чистый титан представлен всего одним пиком. Скорее всего, титан в основном пошел на создание двойного оксида $\mathrm{Fe}_{5} \mathrm{TiO}_{8}$, о чем свидетельствуют его многочисленные пики на дифрактограмме. Результаты элементного анализа покрытия показывают превалирующее количество титана (>78 вес. \%), присутствует 


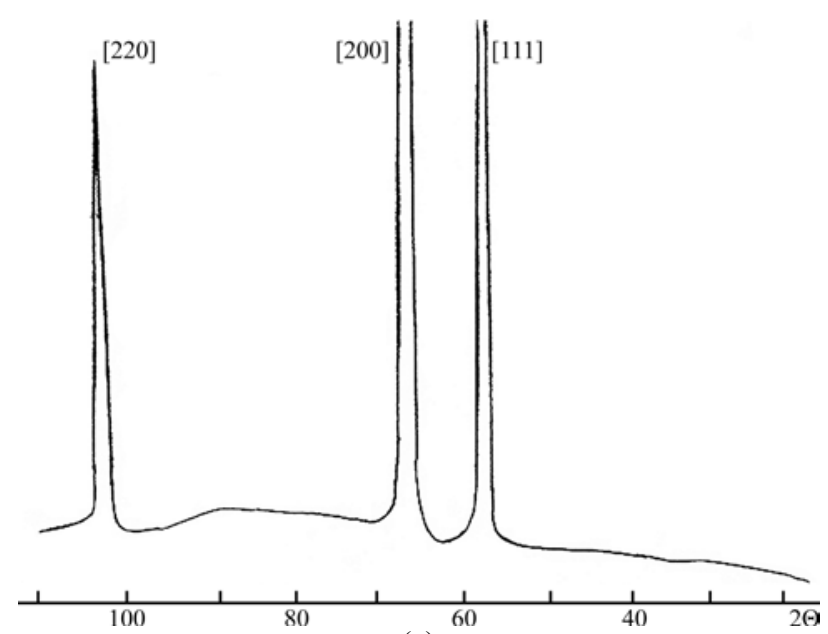

(a)
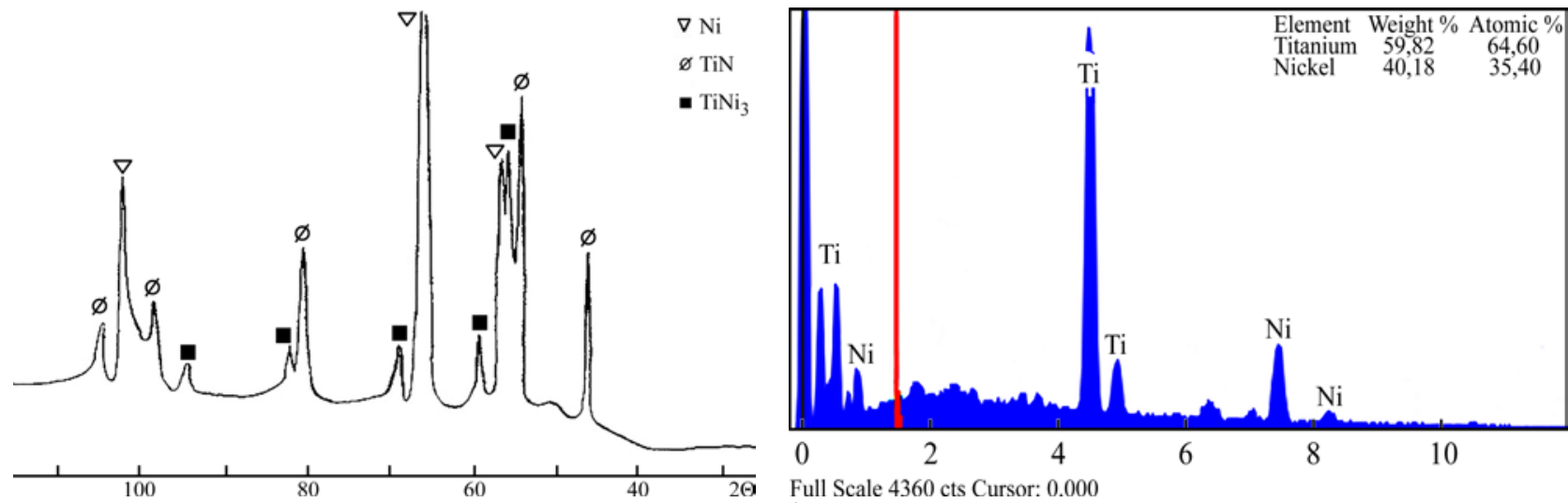

(б)

Рис. 7. Дифрактограммы чистого никеля (a), покрытия $\mathrm{Ni}-\mathrm{Ti}$, режим НЧ, и его EDX-спектр и химический состав поверхности (б).

материал подложки (около 15\%), а никеля в покрытии значительно меньше (почти 6\%).

В случае последовательного легирования стали Ст.3 на том же режиме вначале титаном, а потом никелем наблюдаем близкую картину (рис. 6б), но при этом пик, относящийся к твердому раствору (FeNi) слабее, а пика титана не наблюдается вовсе. Но при этом двойной оксид $\mathrm{Fe}_{5} \mathrm{TiO}_{8}$ представлен более многочисленными пиками. Исследование элементного состава покрытия показывает, что в покрытии больше всего титана (почти 77\%), затем материала подложки $(14,1 \%)$ и всего лишь $\approx 9 \%$ никеля.

Ввиду похожести результатов для Ст.3-Ni-Ti и Ст.3-Ti-Ni было решено исследовать комбинации покрытий Ti-Ni дополнительно.

Так, дифрактограмма необработанного никеля показана на рис. 7а. Если легировать никель титаном на НЧ режиме, чтобы получить больший перенос титана (рис. 7б), то на дифрактограмме электроискрового покрытия наблюдаются самые сильные пики близкой интенсивности, относящиеся к материалу подложки и сформировавшемуся в процессе обработки нитриду титана TiN. Одновременно на поверхности покрытия видны многочисленные, но более слабые пики интерметаллида $\mathrm{TiNi}_{3}$. Исследования

элементного состава покрытия показывают, что в нем содержится больше титана (рис. 7б).

На дифрактограмме образца из титана прежде всего видны собственные линии титана (рис. 8а). Правда, на отдельных дифрактограммах появляется ощутимый пик с $d=1,658$, который можно идентифицировать как смесь оксидов $\mathrm{Ti}_{2} \mathrm{O}_{3}$ и TiO. Не удалось идентифицировать пик с $d=2,83$.

Если титан легировать титаном в НЧ режиме (рис. 8б), то на поверхности покрытия фиксируется резкое ослабление интенсивности линий самого титана - они вообще не наблюдаются у самой поверхности, зато здесь видны (хоть и небольшой интенсивности) пики, соответствующие оксиду $\mathrm{Ti}_{10} \mathrm{O}_{19}$. По мере продвижения от поверхности покрытия вглубь, этот оксид переходит в оксид $\mathrm{Ti}_{2} \mathrm{O}$. Поскольку при температуре выше 400-550 ${ }^{\circ} \mathrm{C}$ титан взаимодействует с азотом воздуха [24], в покрытии формируется нитрид титана $\mathrm{TiN}$, пики которого наблюдаются во всем покрытии сразу же за оксидным слоем $\mathrm{Ti}_{10} \mathrm{O}_{19}$. Интенсивность этих пиков выше, чем у самого титана, что говорит о том, что при легировании титан взаимодействует прежде всего с азотом и в меньшей степени с кислородом воздуха. Наблюдаемое более активное растворение этого 


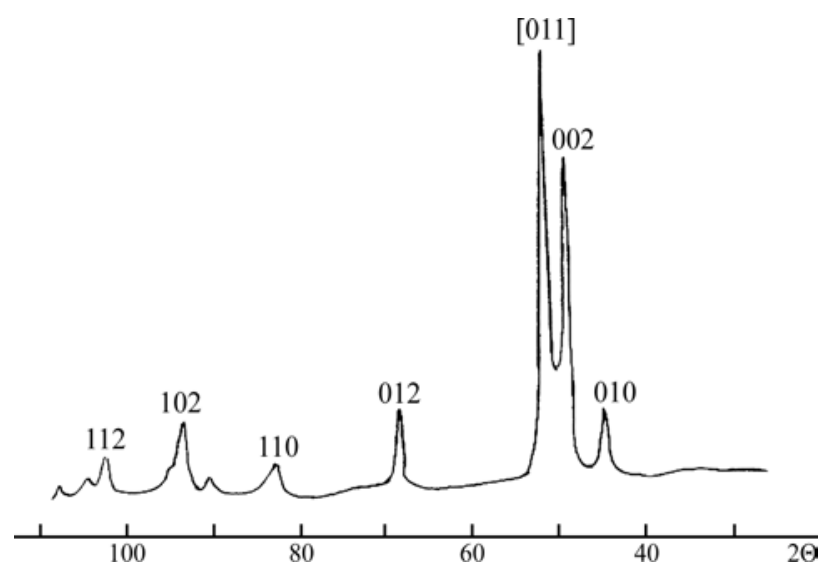

(a)

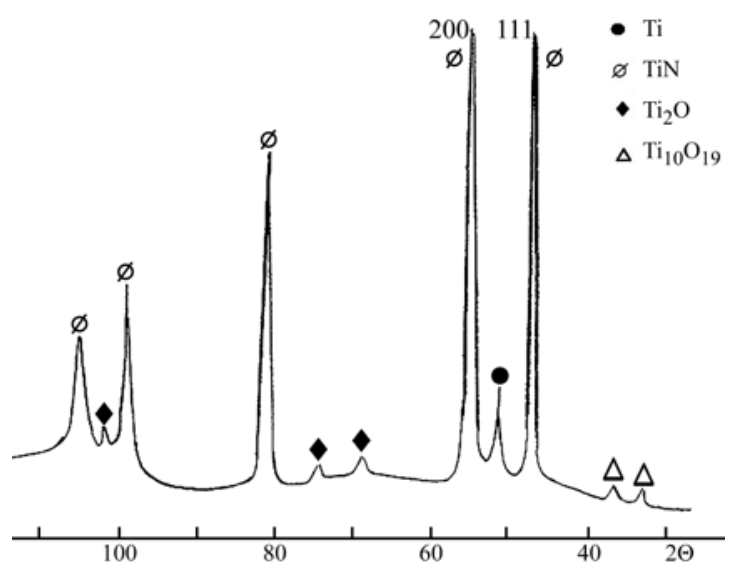

(б)

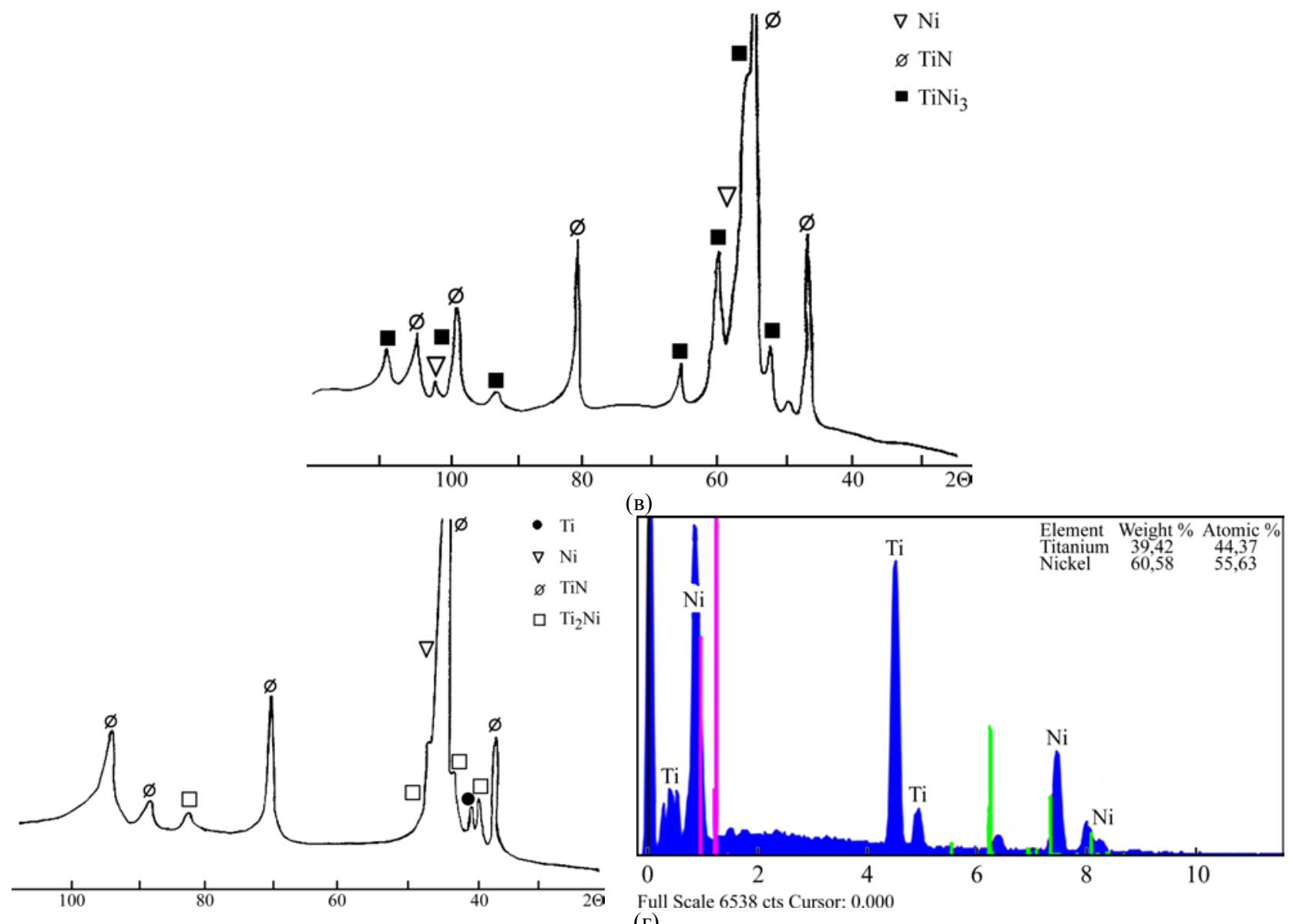

(г)

Рис. 8. Дифрактограммы необработанного титана (а) и покрытий: Ti-Ti, режим НЧ (б); Ti-Ni, режим НЧ (в) и режим ВЧ с его EDX-спектром и химическим составом поверхности (г).

покрытия по сравнению с титаном можно объяснить несколькими факторами: образованием нитрида титана (более активного, чем титан); более развитой поверхностью из-за довольно большой шероховатости и наличием внутренних напряжений.

Как показали исследования, фазовый состав покрытий при легировании титана никелем во многом определяется режимами нанесения (рис. 8в,г). При режиме НЧ (рис. 8в) на дифрактограмме появляются самые интенсивные и многочисленные линии нитрида титана TiN. Никель расходуется на формирование интерметаллида $\mathrm{TiNi}_{3}$, но при этом видны немногочис-

ленные линии и самого никеля. Линий материала подложки не наблюдается.

При легировании на ВЧ режиме (рис. 8г) пик материала подложки (чистого титана) обнаруживается в самом верхнем слое, и он достаточно слаб. Пики самого никеля немногочисленны. Многочисленные и сильные линии свидетельствуют о том, что основная часть титана и никеля расходуется на образование нитрида титана $\mathrm{TiN}$ и интерметаллида $\mathrm{Ti}_{2} \mathrm{Ni}$, которого нет в покрытии при НЧ ЭИЛ (вместо него $\mathrm{TiNi}_{3}$ ). Видно, что на обоих режимах превалирующей фазой является нитрид титана TiN, в значительной степени определяющий коррозионную 
стойкость покрытий. Результаты элементного состава покрытий, полученных на ВЧ режиме, показывают (рис. 8г), что в покрытии никеля больше, чем титана, что, вероятно, связано с их теплофизическими свойствами - значительно более низкой теплопроводностью титана.

\section{ВЫВОДЫ}

Исследован фазовый и элементный состав покрытий, получаемых в ходе ЭИЛ ручным вибратором повышенной частоты.

Установлено, что при легировании стали на ВЧ режиме титаном или ВК8 на поверхности полученного покрытия превалирует материал подложки (70-80\%), при легировании никелем до $35 \%$.

При легировании Ст.3 для уменьшения присутствия материала подложки необходимо обеспечить более интенсивный перенос материала, увеличив время легирования, энергию импульсов и чередование НЧ и ВЧ режимов.

Показано, что двойные покрытия на стали (никель-титан или титан-никель) на ВЧ режиме получаются близкими по своему составу - всегда превалирует титан (около 78\%) и лишь 6-8\% составляет никель.

Установлено, что обработка стали ТНМ-20, ВК8 и титаном с никелем позволяет уменьшить токи коррозии в 2-4,5 раза, но наиболее предпочтительны, с точки зрения снижения коррозионных потерь, твердые сплавы ВК-8 и THM-20.

Легирование на высокочастотном режиме стали Ст.3 электродами из ВК8 (WC92-Co8) позволяет получать износостойкие покрытия благодаря присутствию карбида вольфрама в легированном слое.

Необходимо в дальнейшем исследовать аморфные соединения, образующиеся при легировании стали твердыми сплавами на ВЧ режиме, с целью установления их влияния на коррозионное поведение покрытий и их износостойкость.

\section{КОНФЛИКТ ИНТЕРЕСОВ}

Автор заявляет, что у него нет конфликта интересов.

\section{ЛИТЕРАТУРА}

1. Shepeleva, L., Medres, B., Kaplan, W.D., Bamberger, M., et al., Laser cladding of turbine blades, Surf. Coat. Tech., 2000, vol. 125, no. 1-3, p. 45.

2. Zhu, Y.C., Yukimura, K., Ding, C.X. and Zhang, P.Y., Tribological properties of nanostructured and conventional WC-Co coatings deposited by plasma spraying, Thin Solid Films, 2001, vol. 388, no. 1-2, p. 277.

3. Abad, M.D., Munoz-Marquez, M.A., Mrabet, S.El., Justo, A., et al., Tailored synthesis of nanostructured $\mathrm{WC} / \mathrm{TaC}$ coatings by dual magnetron sputtering, Surf. Coat. Tech., 2010, vol. 204, no. 21-22, p. 3490.

4. Jindal, P.C., Quinto, D.T. and Wolfe, G.J., Adhesion measurements of chemically vapor deposited and physically vapor deposited hard coatings on WC/Co substrates, Thin Solid Films, 1987, vol. 154, no. 1-2, p. 361.

5. Cao, G., Zhang, X., Tang, G. and Ma, X., Microstructure and corrosion behavior of $\mathrm{Cr}$ coating on M50 steel fabricated by electrospark deposition, J. Mater. Eng. Perform., 2019, vol. 28, no. 7, p. 4086.

6. Salmaliyan, M., Ghaeni, F.M. and Ebrahimnia, M., Effect of electrospark deposition process parameters on WC-Co coating on H13 Steel, Surf. Coat. Technol., 2017, vol. 321, p. 81.

7. Pierson, H.O., Handbook of Refractory Carbides and Nitrides: Properties, Characteristics, Processing and Applications, Westwood, NJ, USA: Noyes Publications, 1996, $360 \mathrm{p}$.

8. Johnson, R.N., Alternative Coatings for Wear and Corrosion: The Electrospark Deposition Process, Proc. AESF/EPA Conf. for Environmental Excellence, Orlando, FL, January 2002, p. 38.

9. Lin, N.M., Li, M.L., Zou, J.J., Wang, X.G., et al., Study on fabrication and corrosion resistance of Ni-based alloy coating on P110 steel by electro spark deposition, J. Mater. Eng. Perform., 2013, vol. 22, no. 5 , p. 1365.

10. Jiao, Z., Pterkin, S., Felix, L., Liang, R., et al., Surface modification of 304 stainless steel by electro-spark deposition, J. Mater. Eng. Perform., 2018, vol. 27, no. 9, p. 4799.

11. Radek, N., Shalapko, J. and Kowalski, W., Investigations of the $\mathrm{Cu}-\mathrm{Mo}$ and $\mathrm{Cu}-\mathrm{Ti}$ electrospark coatings after laser treatment, Вестник двигателестроения, 2009, № 1, с. 143.

12. Tang, S.K., The process fundamentals and parameters of electro-spark deposition, M.A.Sc. thesis, University of Waterloo, Waterloo, Ontario, Canada, 2009.

https://uwspace.uwaterloo.ca/bitstream/handle/10012/ 4628/TANG_SIUKEI.pdf?sequence=1

13. Самсонов, Г.В., Витрянюк, В.К., Чаплыгин, Ф.Ч., Карбиды вольфрама, Киев: Наукова думка, 1974. $173 \mathrm{c}$.

14. Ruijun, W., Yiyu, Q. and Jun, L., Interface behavior study of WC92-Co8 coating produced by electrospark deposition, Appl. Surf. Sci., 2005, vol. 240, no. 1-4, p. 42.

15. Radek, N. and Bartkowiak K., Performance properties of electro-spark deposited carbide-ceramic coatings modified by laser beam, Physics Procedia, 2010, vol. 5, part A, p. 417.

16. Pliszka, I. and Radek, N., Corrosion resistance of WC-Cu coatings produced by electrospark deposition, Procedia Eng., 2017, vol. 192, p. 707. 
17. Aghajani, H., Hadavand, E., Peighambardoust, N. and Khamenehasl, S., Electro spark deposition of WC-TiC-Co-Ni cermet coatings on St52 steel, Surf. Interfaces, 2020, vol. 18, no. 3, p. 100392. doi: 10.1016/j.surfin.2019.100392.

18. Scend, M., Corrosion inhibition of copper by potassium ethyl xanthate in acidic chloride solutions, Corros. Sci., 2005, vol. 47, no. 11, p. 2778.

19. Paramonov, A.M. and Koval', A.V., New potentials of the electrospark alloying method for prolonging the service life of cutting tools, Surf. Eng. Appl. Electrochem., 2008, vol. 44, no. 2, p. 87.

20. Коваль, А.В., Исследование коррозионного поведения покрытий, полученных на стали при электроискровом легировании ручным вибратором повышенной частоты, ЭОМ, 2021, т. 57, № 1, с. 44.

21. Уманский, М.М., Золина, 3.К., Сборник задач по рентгеноструктурному анализу, М.: Изд-во МГУ. 1975.

22. Пахомов, В.С., Коррозия металлов и сплавов. Справочник, Т. 1. М.: Наука и технологии, 2013. 448 c.

23. Burkov, A.A., Influence of carbon content of WC-Co electrode materials on the wear resistance of electrospark coatings, J. Surf. Eng. Mater. Adv. Technol., 2012, vol. 2, no. 2, p. 65. doi: 10.4236/jsemat.2012.22012.
24. Лякишев, Н.П., Плинер, Ю.Л., Лаппо, С.И., Легирующие сплавы и стали с титаном, М.: Металлургия, 1986. 232 с.

\section{Summary}

The phase and elemental compositions of electrospark coatings of nickel and titanium deposited on steel, nickel, and titanium, that is, coatings from TiNiMo-20 and WC92-Co8 on steel at high-frequency electrospark alloying are investigated. It is established that the material of the electrode, of the substrate, and the mode of deposition have the main impact on physical and chemical properties of the formed coatings. A positive influence of high-frequency alloying on quality indicators of the processed surfaces is shown. Both the phase and chemical analyses showed availability of the compounds considerably improving corrosion resistance of the processed surfaces. Alloying with WC92-Co8 electrodes at a high frequency makes it possible to obtain an increased content of tungsten carbide in the deposited layer.

Keywords: electrospark alloying, high-frequency alloying, phase structure, chemical structure, steel, titanium, nickel, TiNiMo-20, WC92-Co8 